\title{
Potential of Micro Hydroelectric Generator Embedded at 30,000 PE Effluent Discharge of Sewerage Treatment Plant
}

\author{
M.A. Che Munaaim ${ }^{1}$, N. Razali ${ }^{1}, A$. Ayob $^{1}, N$. Hamidin $^{1}$, and M.A. Othuman Mydin ${ }^{2}$ \\ ${ }^{1}$ School of Environmental Engineering, Universiti Malaysia Perlis, Arau Perlis, Malaysia \\ ${ }^{2}$ School of Housing, Building and Planning, Universiti Sains Malaysia, Pulau Pinang, Malaysia
}

\begin{abstract}
A micro hydroelectric generator is an energy conversion approach to generate electricity from potential (motion) energy to an electrical energy. In this research, it is desired to be implemented by using a micro hydroelectric generator which is desired to be embedded at the continuous flow of effluent discharge point of domestic sewerage treatment plant (STP). This research evaluates the potential of electricity generation from micro hydroelectric generator attached to $30,000 \mathrm{PE}$ sewerage treatment plant. The power output obtained from calculation of electrical power conversion is used to identify the possibility of this system and its ability to provide electrical energy, which can minimize the cost of electric bill especially for the pumping system. The overview of this system on the practical application with the consideration of payback period is summarized. The ultimate aim of the whole application is to have a self-ecosystem electrical power generated for the internal use of STP by using its own flowing water in supporting the sustainable engineering towards renewable energy and energy efficient approach. The results shows that the output power obtained is lower than expected output power $(12 \mathrm{~kW})$ and fall beyond of the range of a micro hydro power $(5 \mathrm{~kW}$ $100 \mathrm{~kW}$ ) since it is only generating $1.58 \mathrm{~kW}$ energy by calculation. It is also observed that the estimated payback period is longer which i.e 7 years to recoup the return of investment. A range of head from $4.5 \mathrm{~m}$ and above for the case where the flow shall at least have maintained at $0.05 \mathrm{~m}^{3} / \mathrm{s}$ in the selected plant in order to achieved a feasible power output. In conclusion, wastewater treatment process involves the flowing water (potential energy) especially at the effluent discharge point of STP is possibly harvested for electricity generation by embedding the micro hydroelectric generator. However, the selection of STP needs to have minimum 4.5 meter head with $0.05 \mathrm{~m}^{3} / \mathrm{s}$ of continuously flowing water to make it feasible to harvest.
\end{abstract}

* Corresponding author: $\underline{\text { arkam } @ \text {,engineer.com }}$ 


\section{Introduction}

Recently, energy crisis related problem such as depletion of fossil fuel, climate change and further increasing demand of electricity supply is continuously raised world-wide [1]. One of the popular alternatives is using the renewable energy resources that avoid from bringing impact to the environment while resolving the problem of energy crisis. The renewable energy sources include wind, solar and hydroelectric power plant is normally used $[2,3]$. The application of micro hydro for electrical generation is something promising for future especially for small scale user.

Micro hydroelectric power is considered as a non-polluting, renewable and environmental-friendly source of energy [4]. According to [5], it is utilized as a source of natural energy since water is the only source that is required by the system and does not cause impact to the environment. Besides, neither a large dam nor a land flooded is required for the application of a micro hydropower system [5]. However, it is capable of consistent in supplying stable electrical energy by only using pressure of treated wastewater from the discharge of sewerage treatment plant. Recently, this system is becoming more popular as it is reliable and involves minimum maintenance and care.

In sewerage treatment plant, the solid waste or the treated sludge which suitable for disposal of reuse are usually processed as fertilizers. On the other hands, the treated water in fact does not exploit in any other usage but only discharge into the river or drain. Hence, there are actually possessed of a high potential of hydropower application in this sector. The treated water can be utilized for generating electricity by a micro hydro power plant before releasing it back to the environment. [6] stated that treated water of sewerage at a high pressure or flowing with a high velocity possess of a high potential energy can be used to run turbine or water wheel attached to generator and therefore of electrical power can be generated.

Micro hydro, as one of the small hydropower systems with a power rating of $100 \mathrm{~kW}$ or less and a 100kW system will produce 100 standard units of electricity in one hour on ideal case [7]. This paper promotes small-scale hydro schemes that desired to generate up to 12 kilowatts as targeted power output. There is approximately $50 \%$ to $65 \%$ of the net power demand for a typical activated sludge wastewater treatment plant is consumed by the aeration system. Hence, if the implementation of micro hydropower system is successful achieved, it can be contributing to a significant figure in term of cost saving for the electrical bill since the system can facilitate in cutting down the expenses of electrical generation of the plant operation especially the consumption from aeration system.

This paper targeted to explain the potential of generating electricity through the micro hydro generator at $30,000 \mathrm{PE}$ sewerage treatment plant by assessing the available parameters on actual site in Perlis, Malaysia that been conducted in 2016.

\section{Materials and methods}

The aim of this research is to identify the potential of micro hydroelectric generator embedded at 30,000 PE effluent discharge of sewerage treatment plant. The plant that has been chosen for this research is located in the Rural Sewerage Treatment Plant (RSTP) at Wang Bintong, KNR059, Jalan Raja Syed Saffi, 01000 Kangar, Perlis Indera Kayangan. Population equivalent that served by this STP facility is given as maximum serving value of 30,000 PE and the normal service value is maintain at 21,000 PE, which is recorded at a percentage of $70 \%$ as compare to the maximum state. The effluent from this STP facility is referring to Standard B (Category II) and direct discharge into river. Total head of difference between effluent discharge point and the connected discharge channel is 3.5 meter. 


\subsection{Preliminary data}

Table 1 indicated the preliminary data obtained from RSTP Wang Bintong, KNR 059 and used for computation of potential power harvested by the micro hydro generator and its feasible payback period.

Table 1. Preliminary data from RSTP Wang Bintong, KNR 059.

\begin{tabular}{|c|c|}
\hline Preliminary data & Values \\
\hline Population equivalent, PE & 30,000 \\
\hline Average flow rate of effluent, $\mathrm{Q}$ & $0.054 \mathrm{~m}^{3} / \mathrm{s}$ \\
\hline Head of effluent, $\mathrm{H}$ & $3.5 \mathrm{~m}$ \\
\hline Gravitational acceleration, $\mathrm{g}$ & $9.81 \mathrm{~m}^{2} / \mathrm{s}$ \\
\hline Density of effluent, $\rho$ & $1000 \mathrm{~kg} / \mathrm{m}^{3}$ \\
\hline Efficiency of turbine, $\eta$ & 0.85 \\
\hline Average total electrical energy consumption per month & $53,004 \mathrm{kWh}$ \\
\hline Average total electrical bill per month & $\mathrm{RM} 22,569.50$ \\
\hline Average rates of electrical bill per kWh usage & $\mathrm{RM} 0.426 / \mathrm{kWh}$ \\
\hline
\end{tabular}

\subsection{Calculation of the potential electrical power output}

Based on head, flow, and constants related to the water density, gravitational acceleration, and efficiency, the electrical power that can be generated from a turbine at the RSTP Wang Bintong was determined using Equation:

$$
P_{e}=P_{h} \times \eta=Q \times H \times g \times \rho_{w} \times \eta
$$

Where,
$\mathrm{P}_{\mathrm{e}}$ is electrical power $(\mathrm{kW})$
$\mathrm{P}_{\mathrm{h}}$ is hydraulic power $(\mathrm{kW})$
$\eta$ is the efficiency of the turbine (unitless)
$\rho w$ is the density of the water $\left(\mathrm{kg} / \mathrm{m}^{3}\right)$
$\mathrm{g}$ is the acceleration due to gravity $\left(\mathrm{m} / \mathrm{s}^{2}\right)$
$\mathrm{Q}$ is the flow of water through the generator $\left(\mathrm{m}^{3} / \mathrm{s}\right)$
$\mathrm{H}$ is the head $(\mathrm{m})$

Electrical power that can be generated is depend on the water flow rate and head besides the gravity and density of the water as constant.

\subsection{Estimation of feasible payback period}

The payback period is obtained by initially identify estimated power generation by the generator and also its contribution to the saving in electrical bill of plant facility based on annual operation. The monthly contribution in term of saving in electrical bill is then compared to the total electrical bill for the plant operation in RSTP Wang Bintong, KNR 059 in order to attain the feasible payback period of the implementation of the generator.

\subsection{Viability of hypothetical micro hydropower scenarios}

In order to define the viability of installing micro hydroelectric power generator for the hypothetical cases of head and flow that were created, three steps were taken. First, potential power generation (in $\mathrm{kWh}$ ) was calculated for all possibilities of flow and head 
combinations within the ranges. These values were calculated based using equation of potential power output. Second, the potential power generation values were converted into savings, using average rates of RM 0.426 per $\mathrm{kWh}$ usage in electrical energy consumption. Yearly savings (rounded to the nearest Ringgit Malaysia) for each combination of artificial head and flow cases computed. Finally, the yearly savings were compared to an estimated capital of investment of RM 150,000. Payback periods were calculated for each of the cases. The hypothetical cases and their payback periods are then listed in tables.

\section{Results and discussions}

\subsection{Potential power output}

From this research, the output power obtained, $1.58 \mathrm{~kW}$ is found to be categorized as pico hydro power which is outside the scope of micro hydro power as shown in Table 1.1. As a result, this plant may not be recommended to implement the system as the outcome may not be satisfied and some modification need to be done before practical implementation. In the meanwhile, other bigger capacity plant shall be proposed in order to suit the criteria for the implementation of the system.

Table 2. Power output calculated from the equation-Equation (1).

\begin{tabular}{|c|c|}
\hline Power output & Values \\
\hline The amount of hydraulic power available in the system, $\mathrm{P}_{\mathrm{h}}$ & $1.85 \mathrm{~kW}$ \\
\hline Conversion of electrical power from hydraulic power, $\mathrm{P}_{\mathrm{e}}$ & $1.58 \mathrm{~kW}$ \\
\hline
\end{tabular}

On the other hands, in order to attain the targeted output power for implementing the system at RSTP Wang Bintong, the minimum flow to coordinate is derived. Rearrange the equation (1) previously of electrical power, the required flow rate is found to be,

$$
Q_{r e q}=P_{r e q} /(H \times g \times \rho \times \eta)
$$

Table 3. The comparison of required flow based on the difference in electrical power required.

\begin{tabular}{|c|c|c|c|c|}
\hline $\begin{array}{c}\text { Electrical } \\
\text { Power } \\
\text { Required, } \mathbf{P}_{\text {req }} \\
(\mathbf{k W})\end{array}$ & Head, H (m) & $\begin{array}{c}\text { Gravitational } \\
\text { Constant, } \mathbf{g} \\
\mathbf{( m}^{\mathbf{2} / \mathbf{s})}\end{array}$ & $\begin{array}{c}\text { Turbine } \\
\text { Efficiency, } \\
\mathbf{\eta}\end{array}$ & $\begin{array}{c}\text { Flow Required, } \\
\left.\mathbf{Q r e q}_{\mathbf{( m}} \mathbf{s} \mathbf{s}\right)\end{array}$ \\
\hline 5.0 & 3.5 & 9.81 & 0.85 & 0.17 \\
\hline 12.0 & 3.5 & 9.81 & 0.85 & 0.41 \\
\hline
\end{tabular}

As shown in the table above, it is observed that a minimum flow rate of $0.41 \mathrm{~m}^{3} / \mathrm{s}$ shall be required at the effluent discharge point to achieve $12 \mathrm{~kW}$ under consideration of the other input data remain as usual. The required flow rate, $\mathrm{Q}_{\mathrm{req}}$ is resulted to be around eight-fold compared to the actual flow rate of effluent, Q if the head is assumed to be maintained as the same, $\mathrm{H}=3.5$ meter. According to [6] earlier, a micro hydro power plant usually generated electrical power with a minimum value of $5 \mathrm{~kW}$. Thus, it is found that the required flow for effluent discharge shall maintained at an average of $0.17 \mathrm{~m} / \mathrm{s}$ in order to fulfil the minimum electrical power generation of micro hydro power if other input data is remained at constant. This value is differing about 3 -fold compared to the actual flow at the effluent discharge at RSTP Wang Bintong, KNR 059. 
Table 4. The comparison of power output based on different head and flow rate in varies locations of facilities.

\begin{tabular}{|c|c|c|c|c|}
\hline Facility & $\begin{array}{c}\text { Gross Head } \\
(\mathbf{m})\end{array}$ & $\begin{array}{c}\text { Flow Rate } \\
\left(\mathbf{m}^{\mathbf{3}} \mathbf{/ s}\right)\end{array}$ & $\begin{array}{c}\text { Power output } \\
(\mathbf{k W})\end{array}$ & References \\
\hline Emmerich, Germany & $3.6-3.8$ & 0.40 & 13 & {$[8]$} \\
\hline Puan Hydro, Korea & 19.6 & 1.18 & 200 & {$[8]$} \\
\hline Poggio Cuculo, Italy & 28.0 & 0.38 & 44 & {$[9]$} \\
\hline Armary, Switzerland & 105.0 & 0.09 & 68 & {$[9]$} \\
\hline $\begin{array}{c}\text { Marchfeldkanal, } \\
\text { Austria }\end{array}$ & 2.0 & 6.00 & 70 & {$[9]$} \\
\hline Llysy Fran, Scotland & 25.0 & 0.16 & 29 & {$[9]$} \\
\hline Sangüesa, Spain & 11.0 & 1.16 & 75 & {$[9]$} \\
\hline $\begin{array}{c}\text { RSTP Wang Bintong } \\
\text {-KNR059 }\end{array}$ & 3.5 & 0.054 & 1.58 & This research \\
\hline
\end{tabular}

The flow rate obtained after conversion is $0.054 \mathrm{~m}^{3} / \mathrm{s}$, which is significantly smaller as it is comparing to the $400 \mathrm{l} / \mathrm{s}$ which is converted as $0.4 \mathrm{~m}^{3} / \mathrm{s}$. It was mentioned that for the micro hydro scheme at a sewerage treatment plant in Emmerich of Germany that able to generate an output power up to $13 \mathrm{~kW}$ [8]. On other hand, according to [6], the estimated power output of $12 \mathrm{~kW}$ can be resulted from a maximum head of up to $30 \mathrm{~m}$ of height and a low water flow rate of $60 \mathrm{l} / \mathrm{s}$ or $0.06 \mathrm{~m}^{3} / \mathrm{s}$. It is therefore the possible output power obtained in the STP at Wang Bintong in this research could not be achieved up to the targeted value of $12 \mathrm{~kW}$ but only $1.58 \mathrm{~kW}$. This is only $12.75 \%$ of the expected outcome. Furthermore, [9] reporting that other facilities in Poggio Cuculo of Italy, Armary of Switzerland, Llysy Fran of Scotland, Sangüesa of Spain and Marchfeldkanal of Austria are able to offer a reasonable output power under range of below $100 \mathrm{~kW}$ (micro hydro power) generated by either high in gross head and/or high in the nominal discharge as shown in Table 4. Thus, the factors of obtaining a smaller output power than targeted value is contributed by a small effluent flow rate and/or low head in the sewerage treatment plant for this research.

\subsection{Feasible payback period}

Table 5 shows the estimated power generation and also its contribution to the saving in electricity bill according to the monthly and annual operation. This can be obtained by using Equation (1) and the electrical power $\mathrm{P}_{\mathrm{e}}$ that can be generated is $1.58 \mathrm{~kW}$ for the particular RSTP Wang Bintong, KNR059 in Perlis.

Table 5. Estimated output for the practical application of micro hydroelectric generator in RSTP Wang Bintong, KNR059.

\begin{tabular}{|c|c|c|}
\hline $\begin{array}{c}\text { Category of } \\
\text { operation }\end{array}$ & $\begin{array}{c}\text { Total Estimated Power } \\
\text { Generated }(\mathbf{k W h})\end{array}$ & $\begin{array}{c}\text { Contribution to the Saving in } \\
\text { Electricity Bill* }\end{array}$ \\
\hline Monthly & $4,550.40$ & RM 1,938.60 \\
\hline Annual & $54,604.80$ & RM 23,261.64 \\
\hline
\end{tabular}

*Currency exchange at RM 4.2 for 1 USD

The estimation of power generated is based on the 24 hours operation and current power utility provider electricity tariff is used to estimate the electricity charges as shown in Table 5 above. It showed in both average monthly and average yearly.

The monthly contribution in term of saving in electricity bill is then compared to the total electrical bill for the plant operation in RSTP Wang Bintong, KNR 059. It is 
discovered the percentage of monthly savings for electricity bill of the plant operation is obtained at $8.6 \%$. Nonetheless, the obtaining output power may be differing from the expected and not an effective outcome, the estimated power output generating by the micro hydropower system still can be contributed to the internal use of STP and eventually facilitated on saving in monthly electricity bill with around RM 1,938.60.

As for the applying of micro hydroelectric generator in the STP at Wang Bintong, with theoretical annual savings of approximately RM 23,261.64, and a total system installation cost is estimated at approximately RM 150,000.00, the payback period for this facility would be around 7 years. [10] defined that staff members at multiple wastewater treatment facilities in Massachusetts were interviewed, whom a plant manager at Deer Island in Boston of MA, O'Brien claims that a reasonable payback period should be between 0 and 10 years. It is thus deemed this project potentially feasible according to the payback period.

\subsection{Viability of hypothetical micro hydropower scenarios}

Cases that had a payback period of five years or less were deemed viable, while cases with payback periods greater than five years were determined to be potentially viable with some modification, or not viable. Table 6 illustrates the viability of the different combinations of hypothetical flow and head cases. A total of 144 hypothetical cases were analysed by previous researchers, with $79.86 \%$ of the cases being viable, $4.86 \%$ being potentially viable with some modification, and $15.28 \%$ being not viable. As displayed in the table, $100 \%$ of flow cases greater than or equal to $0.30 \mathrm{~m}^{3} / \mathrm{s}$ would be viable for the implementation of this micro hydropower project, as long as the available head is within the range of 1.0 meter and above. For cases with average flows less than $0.30 \mathrm{~m}^{3} / \mathrm{s}, 16$ out of the 45 cases were viable $(35.56 \%)$ and 7 were potentially feasible with modification $(15.56 \%)$. More than half $(48.89 \%)$ of the cases with flows less than 0.30 cubic meter per seconds were deemed not viable.

\section{Conclusions}

On the basis of result, the output power obtained is fairly lower than expected output power, $12 \mathrm{~kW}$. The power output estimated is fall beyond of the range of a micro hydro power $(5 \mathrm{~kW}-100 \mathrm{~kW})$ but the computational calculation shows that it is only generating $1.58 \mathrm{~kW}$ of electrical energy. On the other hand, it is also obtained that the estimated payback period is slightly longer whereby the investor need to be waited for around 7 years to have the return of investment or obtaining the profit. The primary factors are due to a lower flow rate, head and population equivalent, PE numbers are available from the selected sewerage treatment plant. Thus, research on other sewerage treatment plant that is available with a higher PE, flow rate and pressure head will contribute to achieve on obtaining the targeted output power. Besides that, it is also discovered that the total saving in monthly electricity bill is estimated at RM 1,938.60 per month or $8.6 \%$ of the average monthly electricity bill. Nevertheless, the obtaining output power may not be considered as an expected and effective outcome, this research has found that the estimated power output generating by the micro hydropower system still can be contributed to the internal use of STP and eventually facilitated on saving in monthly electricity bill. In conclusion, wastewater treatment process involves the flowing water (potential energy) especially at the effluent discharge point of sewerage treatment plant is possibly harvested for electricity generation by embedding the micro hydroelectric generator. 
Table 6. The viability of the different combinations of hypothetical flow and head cases.
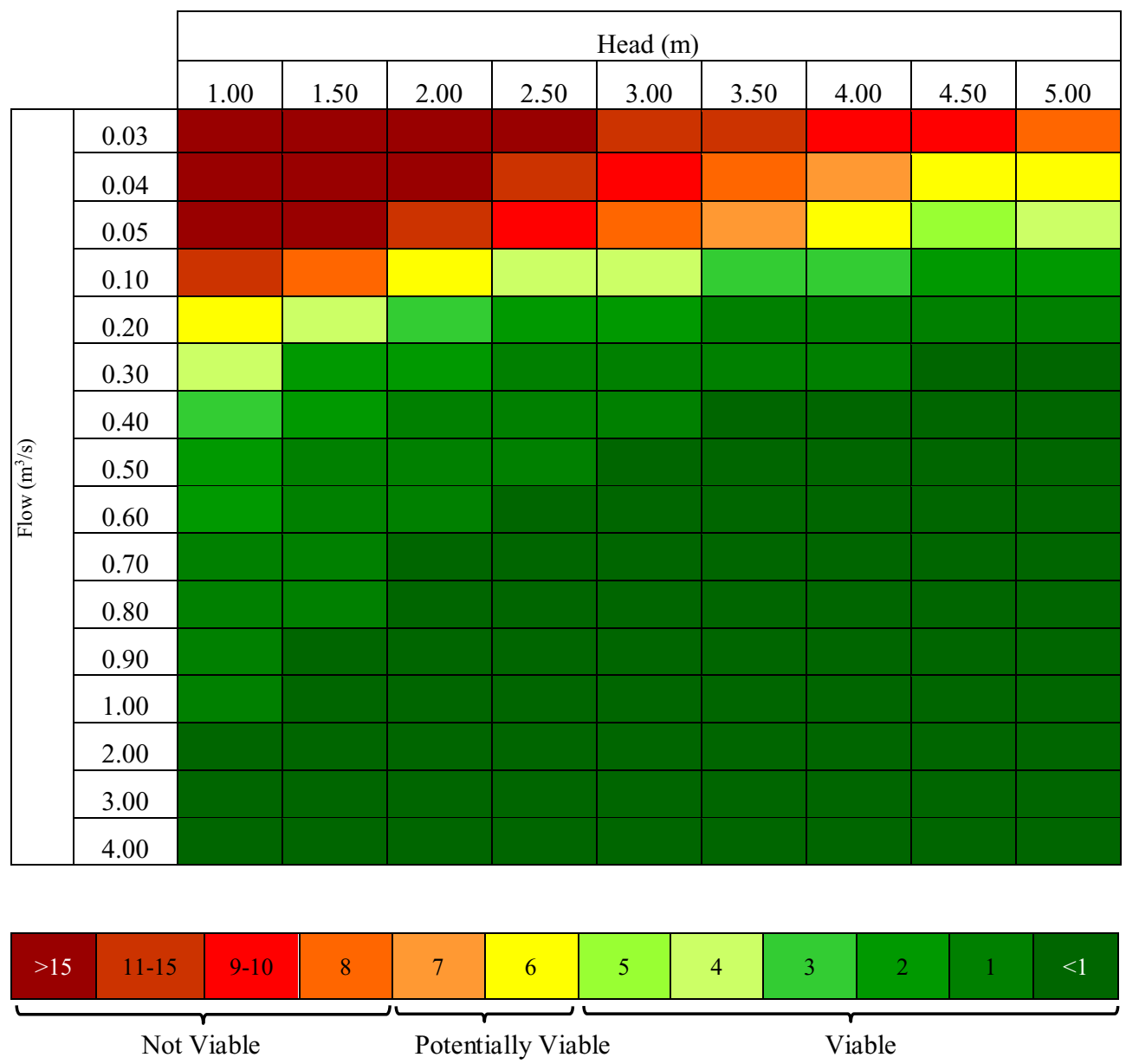

\section{Recommendations}

[10] reported that the sewerage treatment plant at Deer Island practices a combination of renewable energy technologies, and these technologies have the potential to be applied at other facilities. Furthermore, research on the application of micro hydroelectric generator in other sectors such as domestic use, commercial use and public use are suggested in order to provide the alternative way to reduce the energy usage, recycle, reuse and reproduce the energy. It is hoped that this research can be further explore using actual empirical data collection using actual generator embedded to confirm the theorical findings. Next, future research work is proposed for micro, pico or even nano hydro power generation from overhead water tanks of the bathrooms and kitchen to charge the mobiles and small chargeable facilities. This sustainable approach and design is eventually facilitated in preventing the energy deficiency problem and thus benefit the entire social, country and even the future generation.

\section{Commercialization}


From this research, the potential for building a business around harvesting energy in wastewater effluent streams through implementing a micro hydroelectric generator is considered as a feasible approach. This business could easily grow into other markets, notably the potable public water supply in which pressure reduction valves are used to reduce the pressure by dissipating energy rather than capturing it. Industrial processes that are heavy users of water are also one of the possible candidates. The factors of focusing the commercialization of the micro hydroelectric generator system on wastewater is due to sewerage treatment plants (STPs) are large consumers of electrical energy as well as a stable and continuous energy source available, thereby creating a ready use for any energy captured from the effluent stream. Besides that, sewerage treatments plants are famished to diminish their energy consumption, making them are more likely to try the new technology with an acceptable risk mitigation plan.

The authors would like to express our gratitude to Mega Jati Consult Sdn Bhd, Suria Infiniti Sdn Bhd and D'Bumiwater Sdn Bhd for their consultations and to Indah Water Konsortium Malaysia (IWK) for allowing and approved this research at the treatment plant facility.

\section{References}

1. B. A. Nasir, Int. J. Eng. Adv. Techn. 2(5) 39-47 (2013)

2. M. A. C. Munaaim, N. Hamidin, A. Ayob, Jurnal Teknologi (Sciences \& Engineering), 78(5) (2016)

3. W. J. Klunne, Microhydro web portal (2017). \{Assessed online via http://www.microhydropower.net/ on $14^{\text {th }}$ August 2017 \}

4. M. Pauzi M. Kassim, Karam M. Al-Obaidi, M. A. C. Munaaim and Abd. Mokhti Salleh, American Journal of Engineering and Applied Sciences 8(2), 210-222 (2015)

5. S. Eslamian, Urban Water Reuse Handbook- $1^{\text {st }}$ edition (CRC Press, USA, 2016)

6. T. Archana, S. K. Pandey, S. C. Dubey 10(2) 179-183 (2015)

7. Microhydro Power Basics (2017), Home Power web portal \{Assessed online via https://www.homepower.com/articles/microhydro-power/basics/what-microhydropower on $14^{\text {th }}$ August 2017\}

8. C. Bousquet, Cécile; Samora, Irene Manso, Pedro, In Renewable Energy 113, 64-73 (2017).

9. C. Aline, D. Vincent, P. Petras, Integration of Small Hydro Turbines into Existing Water Infrastructures, Hydropower-Practice and Application, INTech \{Assessed online via https:// www.intechopen.com/books/ hydropower-practice-and-application/ integration - of - small - turbines - into - water - infrastructure on 14th August 2017

10. C. Marissa, D. Jessica, H. Christopher, Reclamation of Power in Wastewater Treatment Facilities, Bachelor Degree Desssertation (Faculty Of Worcester Polytechnic Institute, United States, (2014) 